Additional services for Cardiology in the Young:

Email alerts: $\underline{\text { Click here }}$

Subscriptions: $\underline{\text { Click here }}$

Commercial reprints: Click here

Terms of use : $\underline{\text { Click here }}$

\title{
Can we describe structure as well as function when accounting for the arrangement of the ventricular mass?
}

Robert H. Anderson, Edward J. Baker and Andrew N. Redington

Cardiology in the Young / Volume 10 / Issue 03 / May 2000, pp 247 - 260

DOI: 10.1017/S1047951100009197, Published online: 19 August 2008

Link to this article: http://journals.cambridge.org/abstract_S1047951100009197

How to cite this article:

Robert H. Anderson, Edward J. Baker and Andrew N. Redington (2000). Can we describe structure as well as function when accounting for the arrangement of the ventricular mass?. Cardiology in the Young,10, pp 247-260 doi:10.1017/ S1047951100009197

Request Permissions : $\underline{\text { Click here }}$ 


\title{
Can we describe structure as well as function when accounting for the arrangement of the ventricular mass?
}

\author{
Robert H. Anderson, ${ }^{*}$ Edward J. Baker, ${ }^{* *}$ Andrew N. Redington ${ }^{*}$ \\ ${ }^{*}$ Cardiac Unit, Institute of Child Health, University College; ${ }^{* *}$ Evelina Children's Unit, Guy's Hospital, London, UK
}

Keywords: Functionally univentricular heart; functionally single ventricle; double inlet ventricle; atrioventricular valvar atresia; ventricular hypoplasia

I NCREASINGLY, ALL OF US CONCERNED WITH THE diagnosis and treatment of congenital cardiac malformations are seeking to achieve consensus as to how the various anomalies should be defined and described. Certain lesions continue to generate controversy and dispute. Perhaps the entities presently creating most difficulties are those which, with frequency, continue to be described as "single ventricle", or "univentricular heart". As we discussed in our previous review, ${ }^{1}$ it was the use of these terms which created problems when applied, inappropriately in the anatomic setting, to hearts with atrioventricular valvar atresia. The reason why hearts with atrioventricular valvar atresia were described in this fashion, however, stemmed from the accepted use of the terms to account for hearts with double inlet ventricle. Thus, description of the overall group of hearts with double inlet atrioventricular connection as "single ventricles" had become accepted practise. ${ }^{2,3}$ This was despite the fact that most malformed hearts making up this category were well known to possess two chambers within their ventricular mass. The use of "single" to describe such ventricles could only be made logical when one of the chambers was denied ventricular status. One of us, along with his clinical colleagues, championed such a subterfuge $e^{4}$ before realising the artificial and stultifying effect of this convention., 5,6 There are, however, still those who maintain that

Correspondence to: Prof. R.H. Anderson, Cardiac Unit, Institute of Child Health 30 Guilford Street, London WC1N 1EH, UK; Tel: 00-44-207-905-2295; Fax: 00-44-207-905-2324; E-mail: r.anderson@ich.ucl.ac.uk

Accepted for publication 6 March 2000 the rudimentary chamber seen in hearts with double inlet left ventricle represents an infundibulum rather than the incomplete right ventricle. ${ }^{7}$ If we are to achieve the necessary agreement to establish systems of nomenclature which are universally acceptable, and which become interchangeable irrespective of the specific words employed, it is essential that we establish those differences which are simply semantic, as opposed to those which represent true differences in scientific interpretation. It seems that such differences in terms of science do exist with regard to the ventricular mass. So as to resolve these differences, we must agree on the extent of the mass itself, and how to define and describe the chambers within it. This will then permit us to define the number and nature of the components within the normal and abnormal chambers. At the same time, we must agree on the nature of the septums which separate the various components. In this review, we set out our own criterions for distinction of these entities, discussing them in the light of alternative opinions. We show that many hearts can justifiably be described as having a univentricular mass in terms of function, or in other words depend upon a functionally single ventricle. But very few of the lesions described properly in this fashion, when assessed anatomically, are found to possess a solitary ventricular chamber.

The extent, and components, of the ventricular mass

The normal heart is made up of two intertwined muscular pumps. These two entities are the so- 
called right and left sides of the heart, pumping into the pulmonary and systemic circulations, respectively. Each of the muscular pumps has interconnected atrial and ventricular components, which join one another across the atrioventricular junctions (Fig. 1). The outlets from the ventricular components are the frbroelastic arterial trunks, which take their origin at the anatomically discrete ventriculo-arterial junctions (Fig. 2). The ventricular components themselves are then contained within one discrete anatomical unit, the ventricular mass. This functional unit is insulated electrically from the atrial chambers at the atrioventricular junctions, apart from at the site of penetration of the specialised muscular pathway for atrioventricular conduction. The ventricular mass, therefore, can be defined as extending from the atrioventricular to the ventriculo-arterial junctions. The atrioventricular junctions coincide with the hinges of attachment of the atrioventricular valves (Fig. 1). The anatomical ventriculo-arterial junctions represent the areas over which the musculature of the ventricles gives rise to the walls of the arterial trunks. This situation, however, is complicated when compared to the atrioventricular junctions. This is because the leaflets of the arterial valves, unlike the annular hinges of the atrioventricular valves, are attached in semilunar fashion

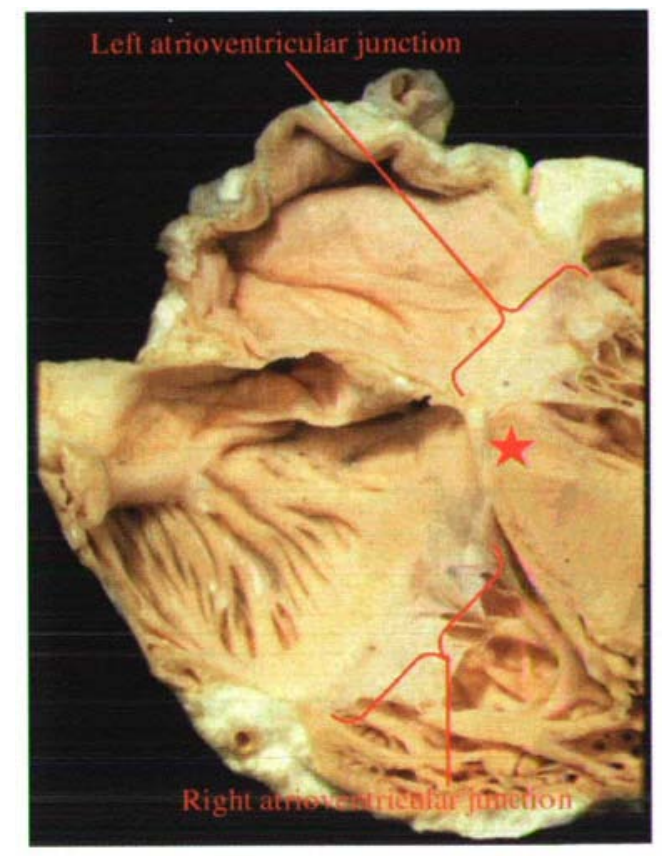

Figure 1.

This section of an adult beart, shown in four-chamber orientation, demonstrates the separateness of the right and left atrioventricular junctions, with the atrial musculature overlapping the crest of the muscular ventricular septum (star) in the area of off-setting of the junctions (see also Fig. 15).

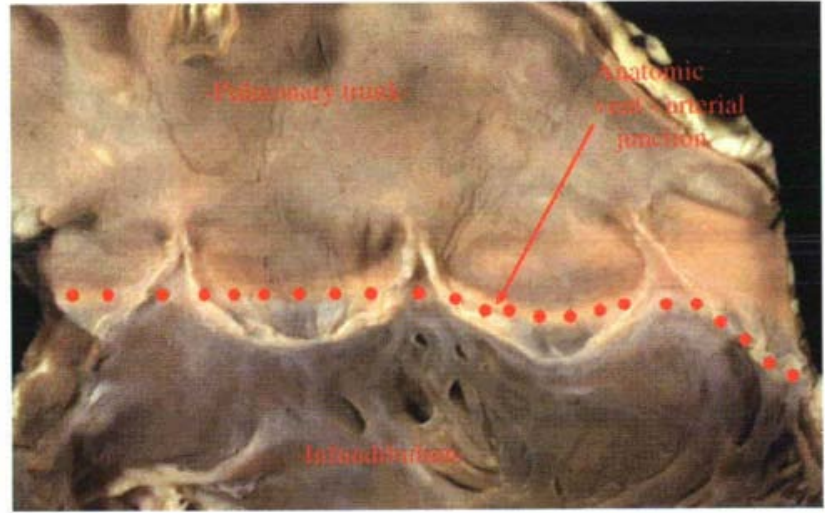

Figure 2 .

In this adult beart, the right ventricular infundibulum has been spread open, and the leaflets of the pulmonary valve removed. Note bow the three semilunar lines of attachment of the valvar leaflets cross the anatomic junction (dotted line) between the muscular infundibulum and the fibro-elastic wall of the pulmonary trunk.

across the anatomic junctions. This results in crescents of ventricular musculature being incorporated within the arterial valvar sinuses, and fibrous triangles of arterial wall included within the apexes of the ventricular outflow tracts, which extend to the sinutubular junctions (Fig. 2). These complications in terms of the discordance between the anatomic and haemodynamic ventriculo-arterial junctions, nonetheless, do not distort the fact that, anatomically and electrically, the ventricular myocardium extends between the anatomic atrioventricular and the ventriculo-arterial junctions. In the normal heart, the ventricular mass as thus defined contains two chambers, the so-called right and left ventricles. Recognition of such chambers as normal ventricles is straightforward. But how are ventricular chambers best described when the heart is malformed, particularly when the chambers themselves may not contain all the components seen in the normal situation? This depends on how the ventricles are themselves described.

\section{Components of the ventricular chambers}

When describing and distinguishing between the ventricles, we have followed the important principle established by Van Praagh and his colleagues, ${ }^{8}$ and called by them "The Morphological Method". In essence, this principle states that a feature which is itself variable should not be used to define another variable feature. A good example of this principle is found when examining the atriums. It is still possible to recognise the left atrium when all the pulmonary veins drain to an extracardiac site. Thus, the pulmonary venous component, itself variable in its location and connection, cannot reliably be used 
as the anatomical arbiter of the morphologically left atrium. The atrial chamber is much better defined anatomically according to the structure of its appendage, which can be distinguished unequivocally according to the extent of the pectinate muscles relative to the atrioventricular junctions.? When we apply this principle to the ventricular mass, we can see that both normal ventricles possess an apical component which receives an inlet, and gives rise to an outlet (Figs 3,4). When we then examine the overall spectrum of congenitally malformed hearts, we find that many ventricles lack a direct outlet, other than through an interventricular communication, as when both arterial trunks are supported by the same ventricle (Fig. 5). In comparable fashion, many hearts also possess chambers which lack any direct inlet, as in double

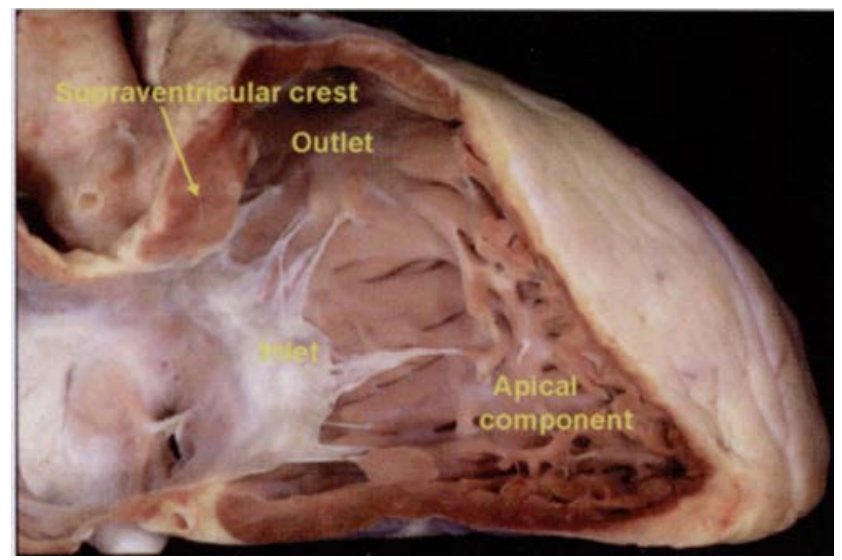

Figure 3.

The normal right ventricle, pumping to the pulmonary circulation, can readily be defined anatomically as baving inlet, apical trabecular, and outlet components. Note the supraventricular crest interposed in the ventricular roof between the inlet and outlet valves.

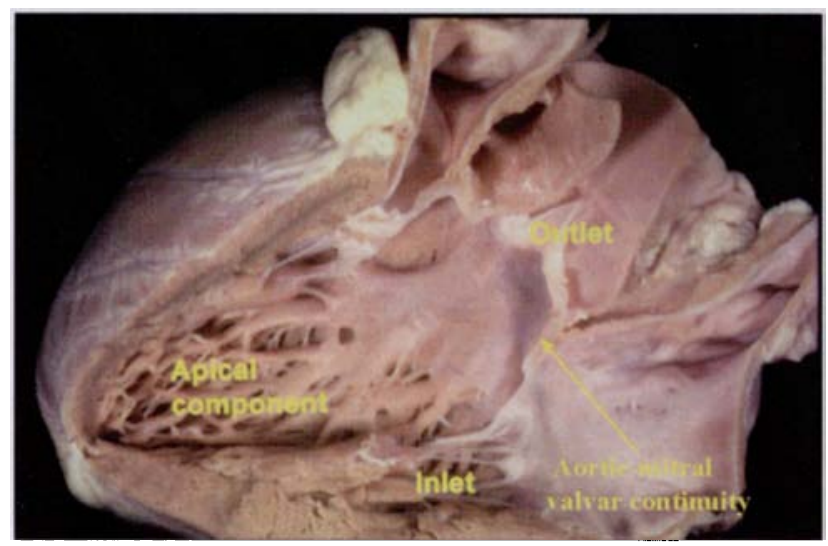

Figure 4.

The normal left ventricle can also be described anatomically in terms of a muscular pump driving the systemic circulation, with inlet, apical trabecular and outlet components, albeit that the leaflets of the inlet and outlet valves are in fibrous continuity (see also Figs. 11 \& 12).

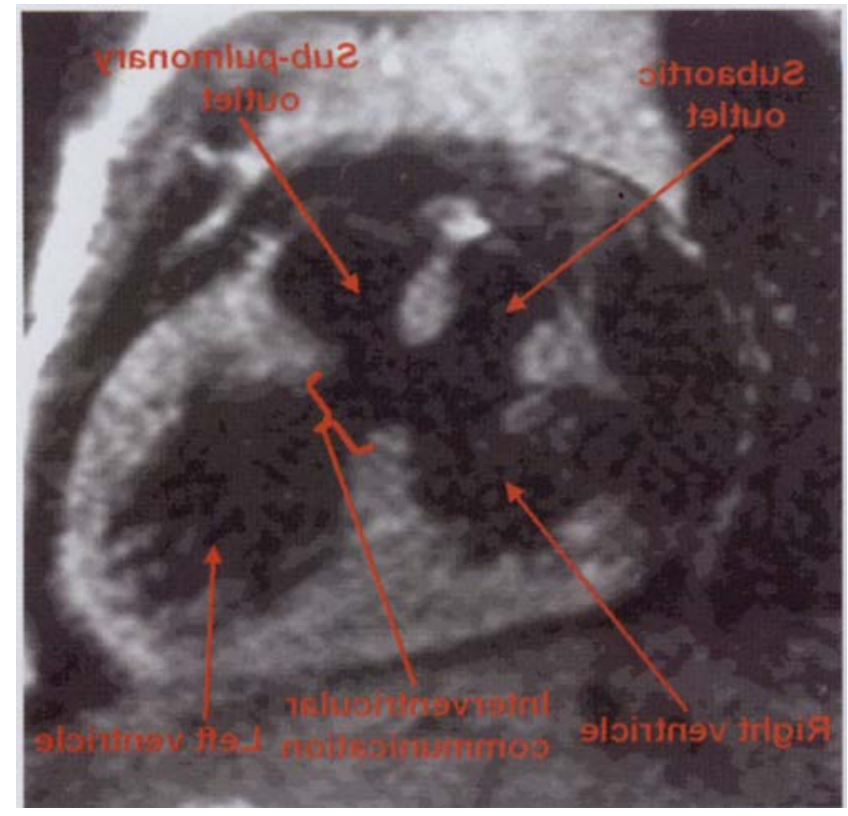

Figure 5.

This resonance image, taken in the frontal plane, shows double outlet from the right ventricle. The interventricular communication is the only direct outlet from the left ventricle, which possess only inlet and apical trabecular components.

inlet ventricle (Fig. 6). Much more rarely, hearts are found in which both atriums connect to the same ventricle, and this ventricle then gives rise to both arterial trunks. In such hearts with double inlet to, and double outlet from, the same chamber, it is usually possible to find the apical component, albeit hypoplastic, of a second ventricle (Figs 7,8 ). All this evidence indicates that, in hearts which are congenitally malformed, there is marked variation in the arrangement of the ventricular inlets and outlets. It

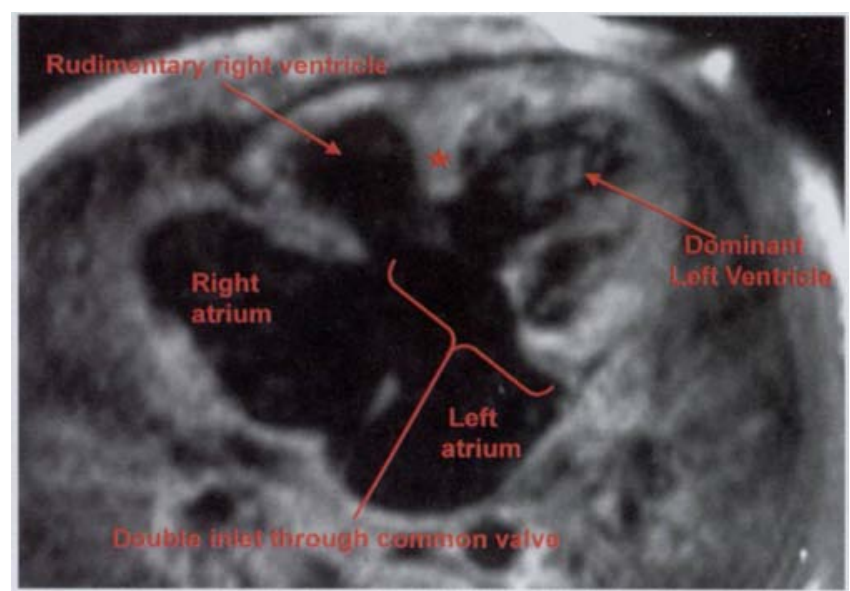

Figure 6.

This resonance image, in "four chamber" plane, shows how both muscular atrioventricular junctions are connected through a common valve to a dominant left ventricle. The apical trabecular septum (star) separates the dominant left from the rudimentary right ventricle. 


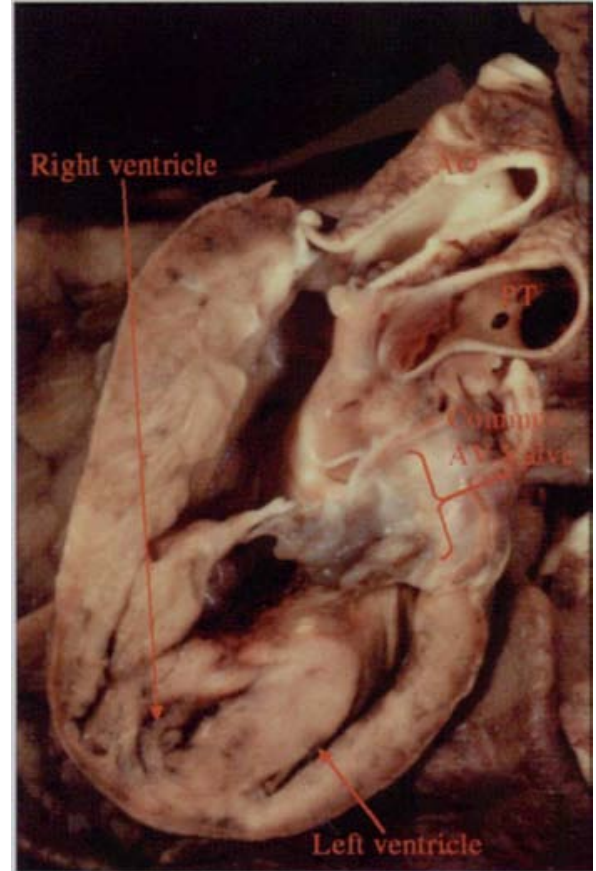

Figure 7.

As in the beart shown in Fig. 6, both atrioventricular junctions in this beart are connected to only one ventricle but, in this beart, the dominant ventricle bas an apical trabecular component of right morpbology, which also supports both outlet components. The incomplete and rudimentary left ventricle is represented only by its bypoplastic apical component, again separated from the dominant ventricle by the apical muscular septum.

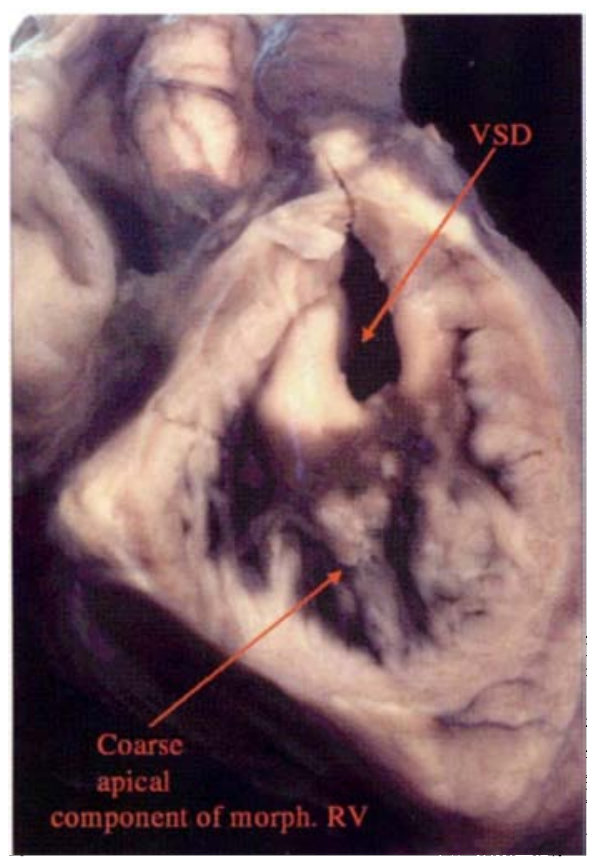

Figure 8 .

This heart had double inlet to, and double outlet from, the dominant left ventricle. This picture shows the rudimentary and incomplete right ventricle $(R V)$, represented only by its coarse apical trabecular component, and receiving blood through the ventricular septal defect (VSD).

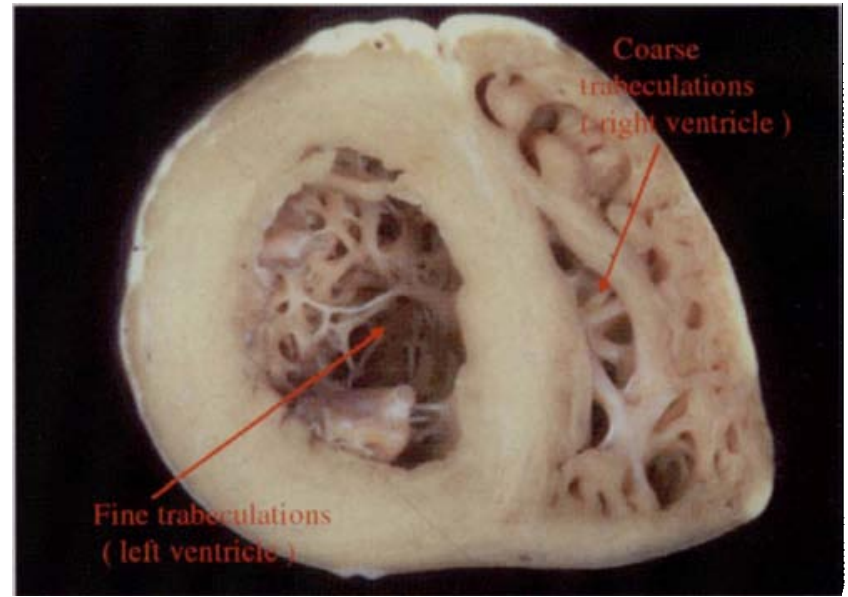

Figure 9.

The apical trabecular components of this infant beart bave been amputated, and are photographed from above. Note bow the nature of the trabeculations within the apical components permits them readily to be distinguished even in the absence of their inlet and outlet components.

is the ventricular apical components which are most constant. Using the principle of the morphological method as established by Van Praagh and his colleagues, ${ }^{8}$ therefore, it is the apical components which should be the final arbiter as to the nature of a ventricular chamber. It so happens that the nature of the trabeculations of these apical components, when compared to each other in the same heart, provides an excellent means by which the morphologist can distinguish the morphologically right from the morphologically left ventricle. The right ventricular trabeculations are much coarser when compared to the fine, criss-crossing, trabeculations of the left ventricle (Fig. 9). This characteristic difference in the apical trabeculations, coupled with the smooth nature of the morphologically left side of the apical septum, readily permits chambers to be recognised as being incomplete morphologically right or left ventricles, even when the apical parts exist in isolation, lacking their inlet and outlet components (Figs 7,8).

It follows from this discussion that ventricles, be they morphologically right or left, are readily described in tripartite fashion, ${ }^{10}$ possessing inlet, apical, and outlet components. The tripartite concept of ventricular description also correlates well with the notion that the ventricles are the pumps to the systemic and pulmonary circuits. To work properly and efficiently, all pumps require valves. Those pumps with inlets and outlets, such as the cylinders of an automobile engine, require valves for each portal. So it is with the ventricular pumps. Traditional wisdom, however, had dictated 
that the ventricles were bipartite in their construction, each possessing a sinus and a conus. How does the morphological evidence relate to these concepts of bipartite as opposed to tripartite ventricular construction?

\section{The structure of normal and abnormal ventricles}

When we examine the normal ventricles, there are no distinct landmarks on their walls which demarcate the divisions within them. When examining the overall structure of each chamber, nonetheless, and taking note of the parietal as well as the septal components, then the inlet components, extending from the atrioventricular junctions to the distal attachments of the valvar tension apparatus, can be recognised as being discrete from the apical components, whilst the outlet components are equally well seen on the basis of providing support for the semilunar leaflets of the arterial valves, and again are seen as being separate from the apical components. There are, of course, differences to be found in the arrangements of these components within the morphologically right and left ventricles. In the right ventricle, it is an easy matter to recognise the extent of the inlet component, and to note its separation from the extensive smooth-walled infundibulum, the latter forming the outlet to the pulmonary trunk (Fig. 10 ). Whilst the coarse nature of the trabeculations are best seen within the apical component of the

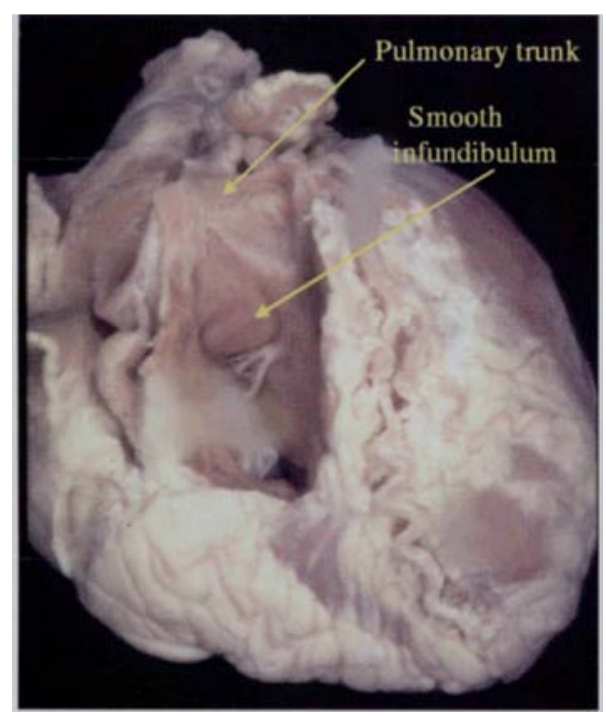

Figure 10.

This adult buman heart has been dissected to show the smooth infundibular component of the right ventricle giving rise to the pulmonary trunk, and separating the pulmonary valvar leaflets from the tricuspid valve. ventricle, the walls of the inlet component are also trabeculated, albeit that the distal part of the infundibulum is smooth walled. In the left ventricle, the divisions are not so obvious. This is because, so as to incorporate both inlet and outlet components within the circular short axis profile of the ventricular chamber, it is necessary for the two to overlap (Fig. 11). The extent of the left ventricular inlet is then seen to best advantage when examining the parietal surface of the ventricle (Fig. 12). The outlet component, furthermore, is much abbreviated when compared to the arrangement seen within the right ventricle.

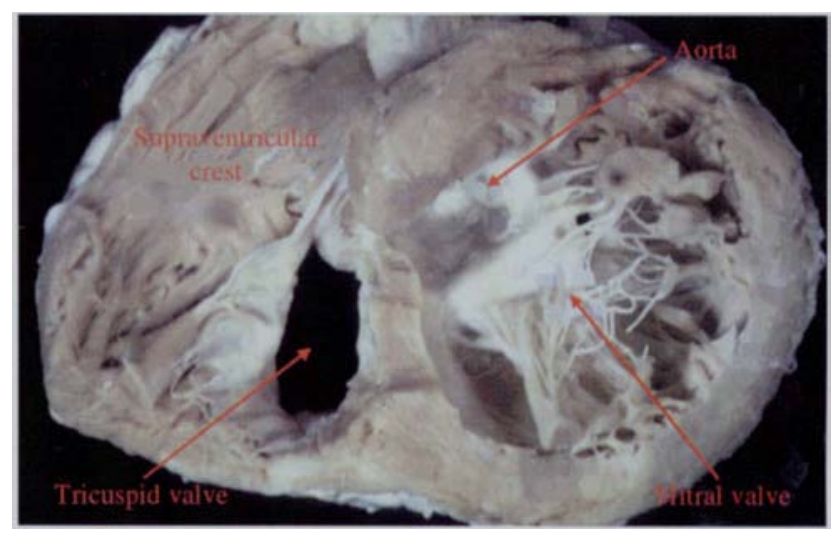

Figure 11.

The short axis of the ventricular mass is shown from the apex in left anterior oblique orientation. Note bow the subaortic outlet component on the left ventricle interposes between the mitral valve and the septum, whereas the tricuspid valve is directly adberent to the muscular septum (See also Fig. 17). Note the fibrous continuity between the leaflets of the aortic and mitral valves.

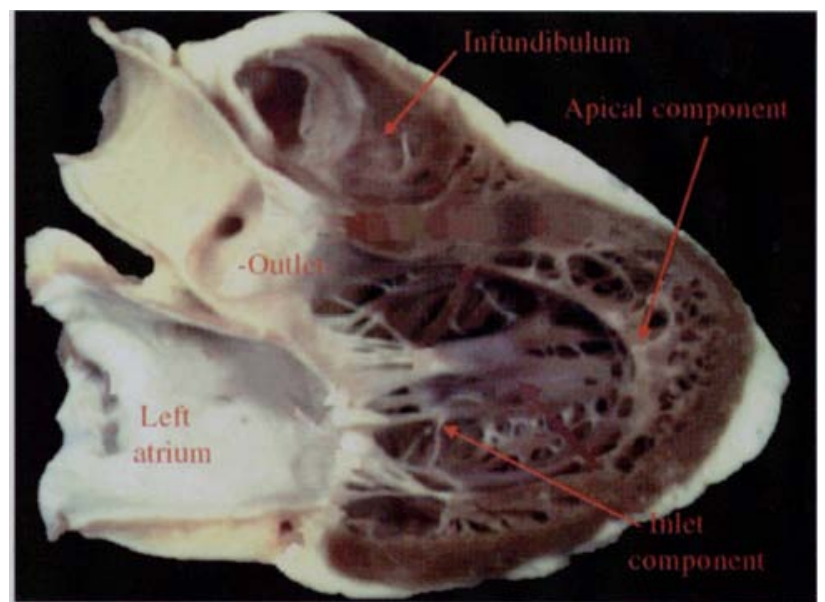

Figure 12.

This is the parietal component of the left ventricle, which has been bisected by a cut along its own long axis. Note the extensive inlet component and the much abbreviated outlet component, along with the fibrous continuity between the leaflets of the aortic and mitral valves. See also Fig. 11. 
This reflects the fibrous continuity almost always found between the leaflets of the aortic and mitral valves (Figs 11,12). Despite its abbreviated nature, nonetheless, there is always a discrete outlet component to be found in the left ventricle between the proximal part of the hinges of the valvar leaflets and their distal attachment at the sinutubular junction (Fig. 13).

If it is difficult always to distinguish the boundaries of the ventricular components when examining the entirety of the chambers, it is even harder to separate the normal septum in comparable fashion. In the past, the normal ventricular septum was frequently described on the basis that it, like the ventricles themselves, possessed inlet, apical, and outlet components. ${ }^{11}$ Subsequent reflection on the best definition of a septal structure ${ }^{12}$ calls into question these earlier accounts. We know that chambers within the heart can be separated from each other by inflections of their walls. An example of this arrangement is seen in the superior rim of the oval fossa. Traditionally, this area has been called the "septum secundum". Incisions in this region, nonetheless, transgress into extracardiac space (Fig. 14). The area is a fold, rather than a true septum. It is the flap valve of the oval fossa which provides the paradigm for definition of a septum, since this part can be removed without exiting from the cavities of the heart. Indeed, removal of the flap valve creates an artificial septal defect. When examined in this light, it then becomes evident that

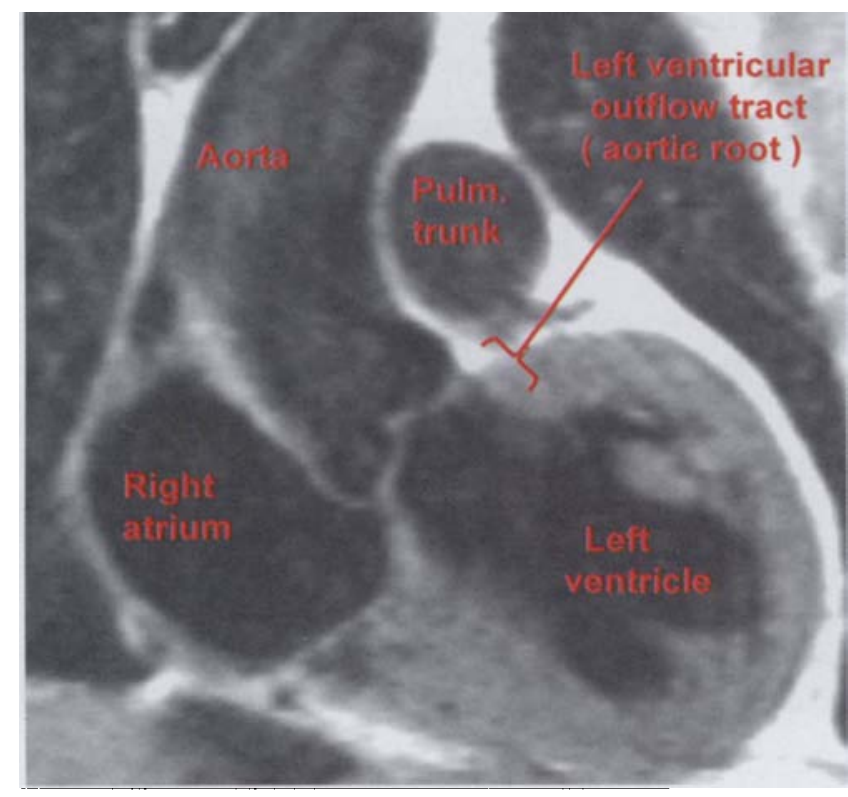

Figure 13.

This resonance image shows bow the outlet component of the left ventricle extends from the basal attachments of the aortic valvar leaflets to the sinutubular junction (see also Fig. 2).

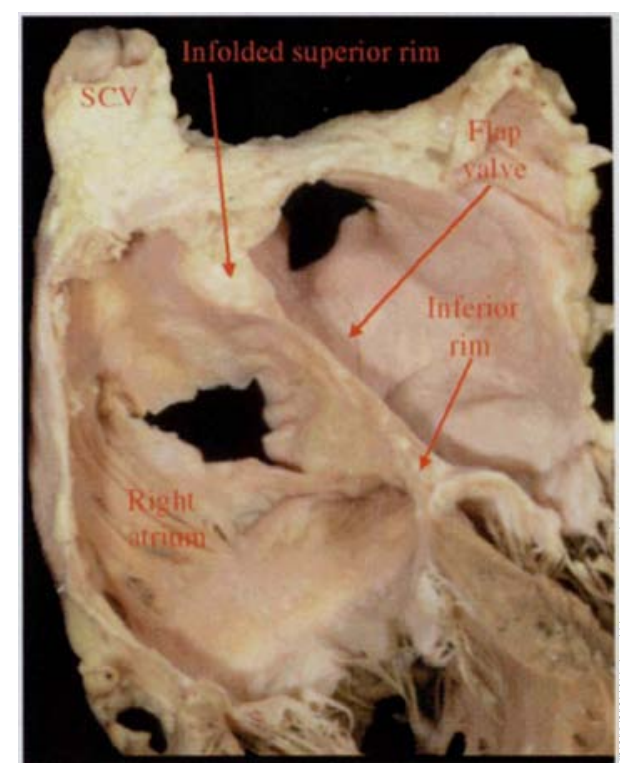

Figure 14.

This four chamber section shows bow the flap valve and inferior rim of the atrial septum interpose between the cavities of the right and left atrial chambers, whereas the superior rim, the so-called "septum secundum", is really a deep infolding, filled with fat, between the superior caval vein and the right pulmonary veins.

the antero-inferior border of the oval fossa, the area we had previously described as the muscular atrioventricular septum, for its greater part is similarly not a true septal structure. This is because a fibrofatty tissue plane extends from the inferior atrioventricular groove into the triangle of Koch, carrying within its interstices the artery to the atrioventricular node. When cut in cross-section, most of the area can be seen to be an atrioventricular muscular sandwich, which masquerades as a septal structure (Fig. 15).

When these examples of septal and pseudoseptal structures are considered in the light of the ventricular septum then, in the normal heart, it is possible anatomically only to distinguish between its muscular and fibrous components, the latter part usually described as the membranous septum (Fig. 16). Very little of the muscular septum can be distinguished as an inlet septum in the normal heart because, in consequence of the deeply wedged location of the normal subaortic outflow tract (Fig. 11 ), the postero-inferior part of the septum is interposed between the inlet of the right and the outlet of the left ventricles (Fig. 17). It is similarly impossible, in the normal heart, to demarcate any specific part of the muscular septum as being an outlet septum. This is because the extensive subpulmonary infundibulum is a free-standing sleeve, with a fibro-adipose tissue plane separating its apparently "septal" components from the sinuses of 


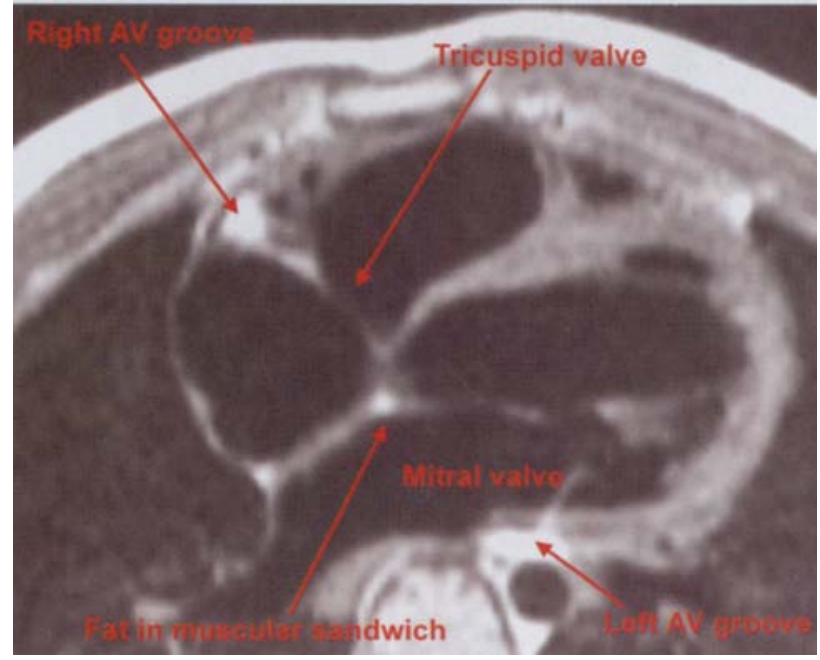

Figure 15.

This resonance image, in four-chamber projection, shows the bright signals from the extracardiac fat in the right and left atrioventricular grooves, but also in the apparently septal area, demonstrating that this is really a muscular atrioventricular sandwich (See Fig. 1).

the aortic valve, rather than interposing between the cavities of the right and left ventricles (Fig. 18).

If the different components of the muscular septum are not visible in the normal heart, however, the evidence of their separate existence is well seen in hearts which are congenitally malformed. Indeed, it is the examination of such malformed hearts, in which the "building blocks" are seen in isolation, and hence can be recognised by the process of subtraction, which provides the

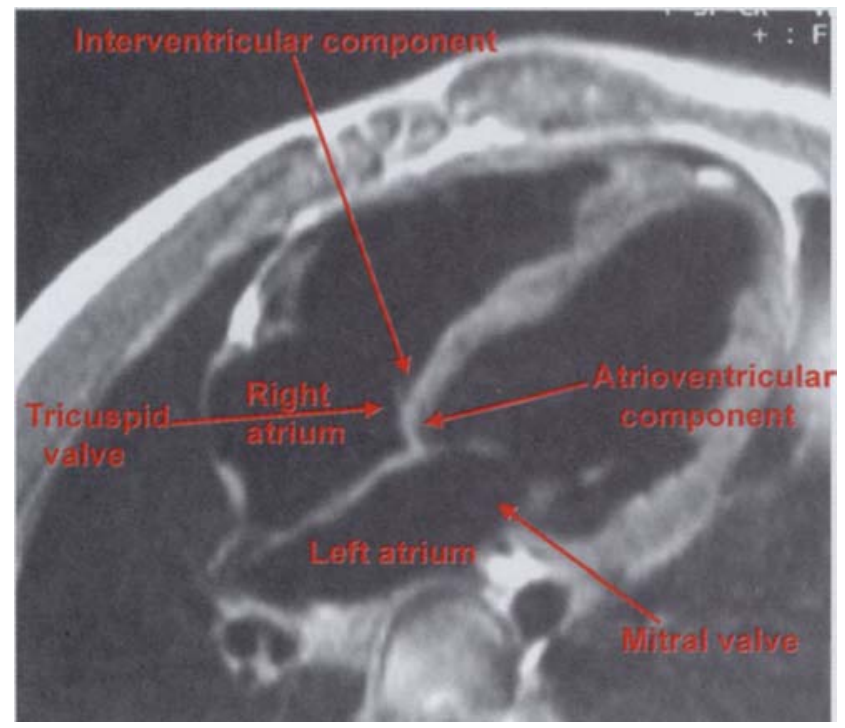

Figure 16.

This resonance image, again in four-chamber projection, shows bow the attachment of the septal leaflet of the tricuspid valve divides the fibrous membranous septum into atrioventricular and interventricular components.

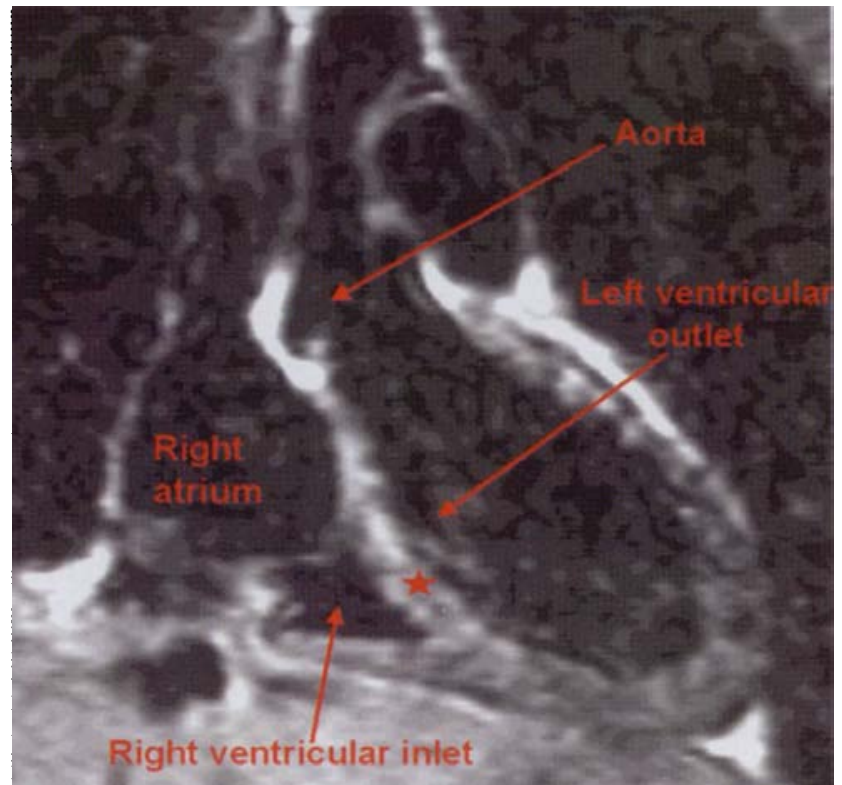

Figure 17.

This resonance image, in frontal projection, shows how the posteroinferior part of the muscular ventricular septum separates the inlet of the right ventricle from the subaortic component of the left ventricle (See also Fig. 11).

strongest evidence in support of the tripartite nature of ventricular construction.

Thus, in hearts with double outlet from the right ventricle, the outflow tract of the left ventricle is represented by the interventricular communication.

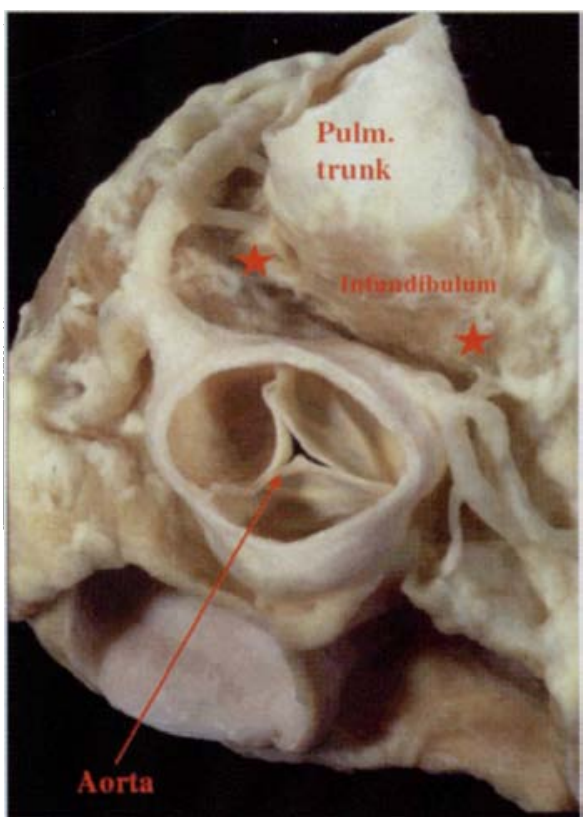

Figure 18.

This normal adult beart is shown from above having deflected forward the free-standing sleeve of subpulmonary muscular infundibulum. Note the extracardiac tissue plane (between stars) separating the infundibulum from the sinuses of the aortic root. 
In these hearts, the postero-inferior part of the muscular ventricular septum then separates the two ventricular inlets, and is justifiably described as a muscular inlet septum (Fig. 19). When the outlets of such hearts are examined, then it is also possible to define a muscular septum, which can be removed without exiting from the cavity of the heart, and which separates the subaortic and subpulmonary outlets. Such a septum is a true muscular outlet septum, but is no longer an interventricular septum, since it is positioned exclusively within the right ventricle (Figs 19,20). A similar arrangement of the muscular outlet septum as a right ventricular structure, frequently discrete from the free-standing subpulmonary muscular infundibulum, is also to be found in tetralogy of Fallot. ${ }^{13}$ Arguments have raged for sometime as to whether the subpulmonary infundibulum is long or short in the setting of tetralogy of Fallot. ${ }^{14,15}$ Our own echocardiographic measurements, ${ }^{13}$ along with those performed during life some time ago by Isaaz and his colleagues, ${ }^{16}$ have shown that, when studied in series of patients, the subpulmonary infundibulum in tetralogy of Fallot is longer than in the normal heart, albeit much narrower. In certain patients, nonetheless, the infundibulum can be short, or even absent. What is now beyond question, however, is that the muscular outlet septum, defined as a muscular intracardiac shelf separating the subaortic and subpulmonary

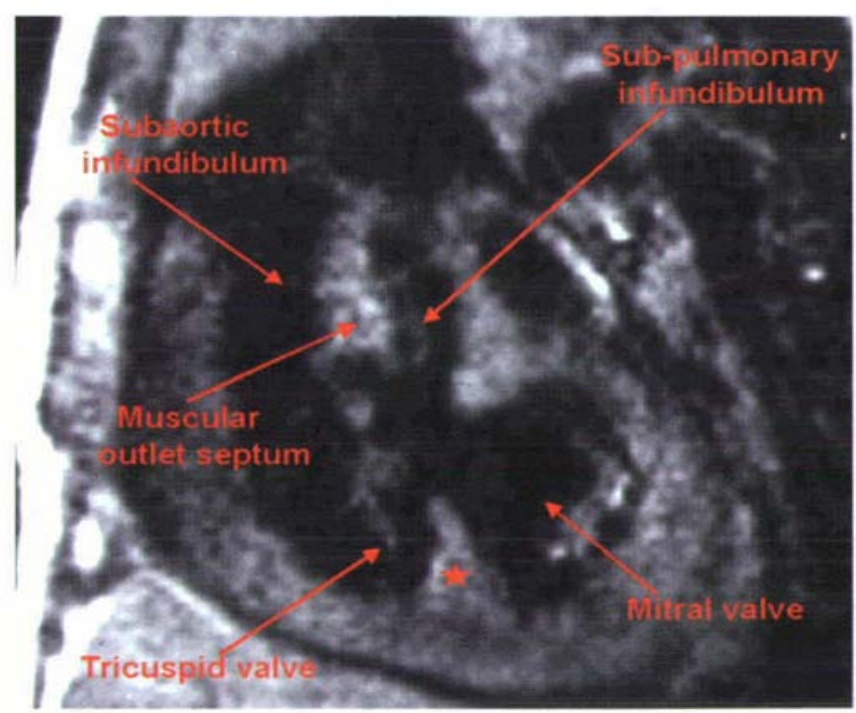

rigure Iy.

This resonance image, in frontal plane, shows double outlet from the right ventricle with bilateral infundibulums. Note that the muscular septum (star) is now directly interposed between the inlets because both outlets are committed to the right ventricle (Contrast with Figs $11 \mathrm{E}$ 17). The muscular outlet septum, bowever, is exclusively a right ventricular structure.

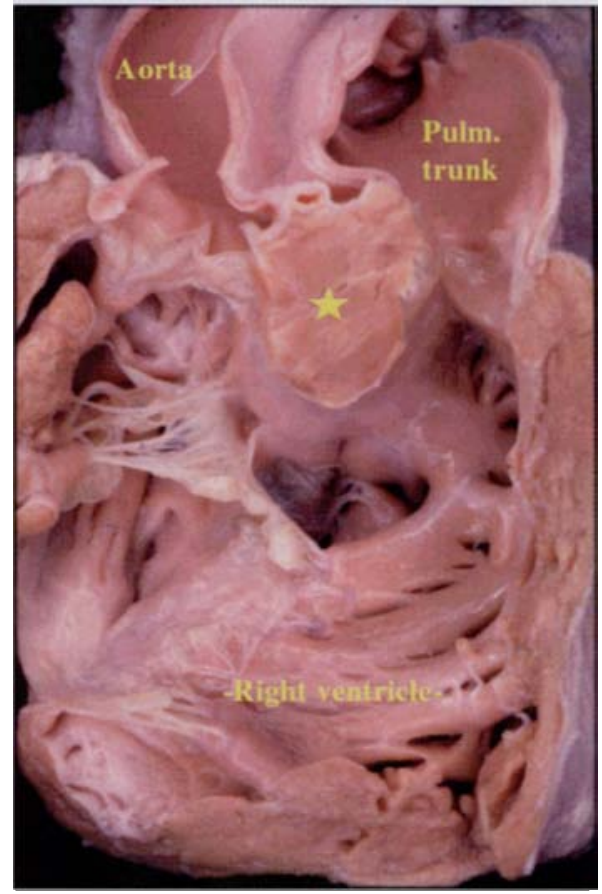

Figure 20.

This section, in frontal plane, from an anatomic specimen with double outlet right ventricle confirms the right ventricular position of the muscular outlet septum (star). See also Fig. 19.

outlets, is seen to its best advantage in hearts with tetralogy of Fallot or double outlet right ventricle, not being definable in its own right in the normally structured heart.

The larger part of the muscular septum of the normal heart, therefore, is the apical septum. This is the part of the septum which, on its crest, carries the atrioventricular conduction axis. It is nourished by the septal perforating branches of the anterosuperior interventricular (left anterior descending) artery. It is reinforced on its right ventricular aspect by the extensive muscular strap which we call the septomarginal trabeculation, and which in the United States of America is called the septal band. The question remains as to whether this septum, or its rudiment, is also to be found in hearts with double inlet ventricle. This answer to this conundrum will resolve also the question about whether these hearts are not only functionally univentricular, but possess a solitary ventricle on anatomic grounds.

\section{Ventricular structure in the setting of double inlet ventricle}

As emphasised in our introduction, it is in hearts with double inlet that the way we describe and divide the ventricles remains most contentious. It 
used to be accepted that the very presence of double inlet ventricle was the criterion for definition of "single ventricle". 2,3 It was on the basis of this conventional wisdom that a group of investigators from Europe, including the first aurhor of this review, constructed formidable conventions to justify the existence of double inlet right ventricle as a "univentricular heart". ${ }^{17}$ It came as somewhat of a surprise, therefore, to find this concept roundly criticised by Van Praagh and his colleagues, ${ }^{8}$ since it was Van Praagh, albeit working with a different group of collaborators, who had first promoted the arrangement of double inlet as the defining feature for "single ventricle". ${ }^{2}$ But the logic emphasised in their criticism, namely that "large right ventricle, together with small left ventricle, does not equal single ventricle", was inescapable. Having accepted this logic, the European group then realised that the same approach must be applicable with equal force to hearts having double inlet left ventricle ${ }^{(5,6)}$. In this context, careful measurements had already shown that the smaller chamber in hearts with double inlet left ventricle was directly comparable to the chamber long recognised as the small right ventricle in hearts having tricuspid atresia, when the atresia was the consequence of absence of the right atrioventricular connection. ${ }^{18}$ Reconsideration of the approach to description then revealed that, in the hearts with dominance of the left ventricle, it was the atrioventricular connections, rather then the ventricular masses, which were truly univentricular. ${ }^{5,6}$ Van Praagh and his colleagues, however, continued to insist that, in such hearts, the left ventricle was still justifiably described as a single ventricle, since the second rudimentary chamber was an infundibulum rather than the rudiment of the right ventricle. ${ }^{7}$ Indeed, his colleagues from Boston have recently extended this concept still further. ${ }^{19}$ They argued that, in the normal heart, the infundibulum of the pulmonary trunk includes a trabecular component which extends to the apex. In their opinion, the infundibulum, rather than representing the free-standing muscular sleeve supporting the leaflets of the pulmonary valve, is better defined as all of the right ventricle distal to the septal band and its apical extension. On this basis, they suggested that septal defects opening to the left ventricle from the apex of the right ventricle were properly defined as infundibulo-ventricular defects. ${ }^{19}$

Is, therefore, the anterior chamber seen in hearts with double inlet left ventricle, and the commonest form of tricuspid atresia, no more than the normal infundibulum, or is it a rudimentary right ventricle with both apical and outlet components? As already intimated, the answer to this question is provided by consideration of the nature of the septum between the two chambers. If the anterior chamber is the infundibulum, then it follows inexorably that the septum separating it from the left ventricle must be the infundibular, or outlet, septum. In contrast, if the chamber is a rudimentary right ventricle, with apical and outlet components, then the septum will similarly possess apical and outlet parts. All the evidence of which we are aware points to the septum having these latter two moieties.

Thus, the apical part of the muscular ventricular septum in hearts with double inlet left ventricle (Fig. 21) and tricuspid atresia (Fig. 22) carries on its crest the insulated muscular pathway for atrioventricular conduction. It is nourished by perforating septal arteries originating from the interventricular arteries. It has characteristic apical trabeculations on each of its surfaces, with the left ventricular surface being smooth in its upper parts.

Further evidence to support this notion comes from studies of the developing normal human heart. It is known that, at early stages of development, the embryonic interventricular foramen is demarcated by a ring of cells which react positively to an antibody derived from the nodose ganglion of the chick. ${ }^{20}$ At the stage at which this ring is first defined (Fig. 23), the developing atrioventricular junctions are unseptated, and are joined exclusively to the developing left ventricle. At this stage, the outlet component, exclusively supported by the distal limb of the primary heart tube, is similarly unseptated. Thus, there is no outlet septum formed at this stage of development. Already, however, the developing right ventricle possesses an apical component which is distal to the ring of positively

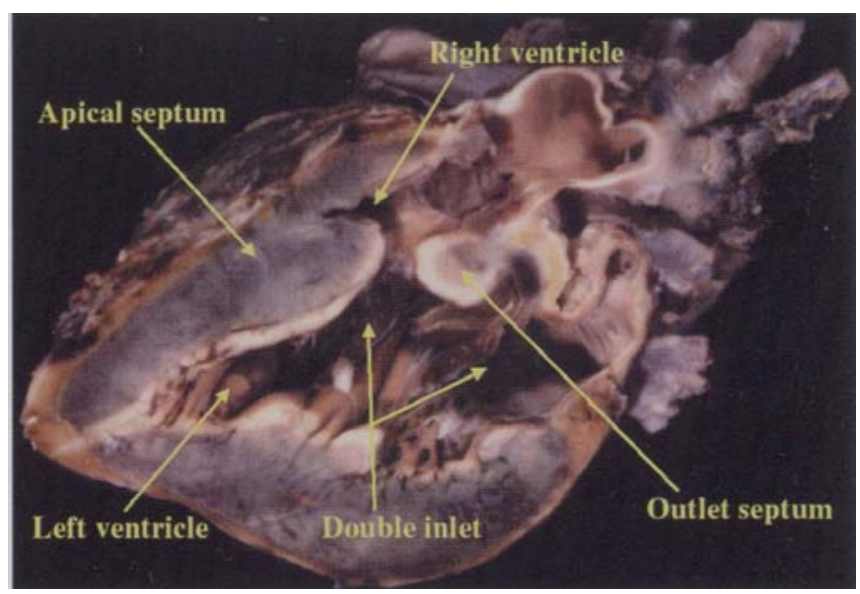

Figure 21.

This section, taken along the long axis of the dominant left ventricle, shows bou the septum between dominant and rudimentary ventricles bas apical and outlet components in the setting of double inlet left ventricle and discordant ventriculo-arterial connections. 


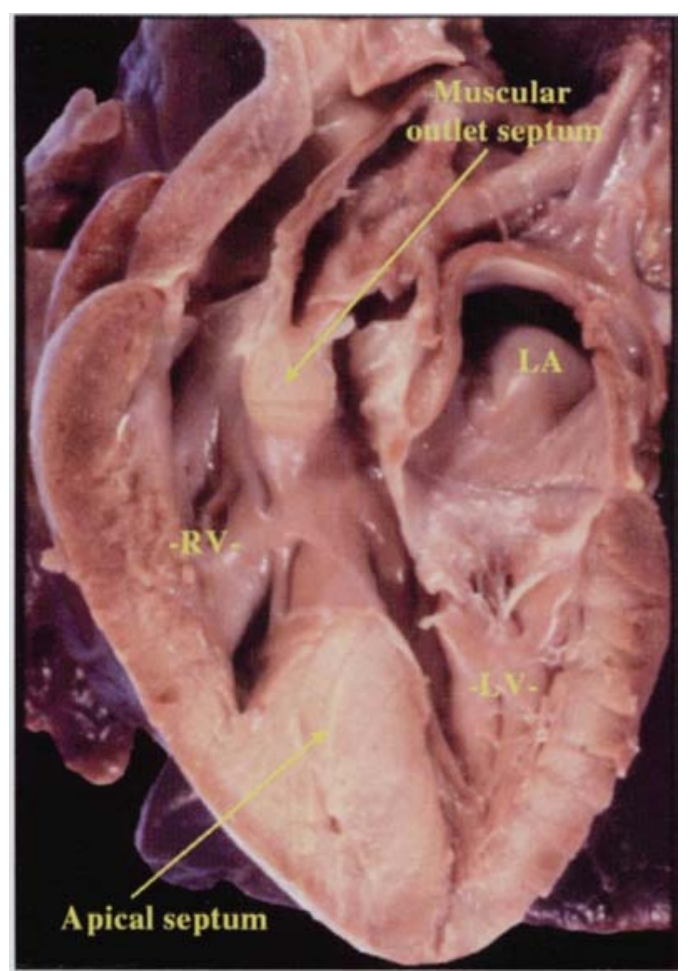

Figure 22.

This section, again in the long axis of the dominant left ventricle, shows the apical trabecular and outlet components of the muscular ventricular septum in the setting of absence of the right atrioventricular connection (tricuspid atresia) with discordant ventriculoarterial connections.

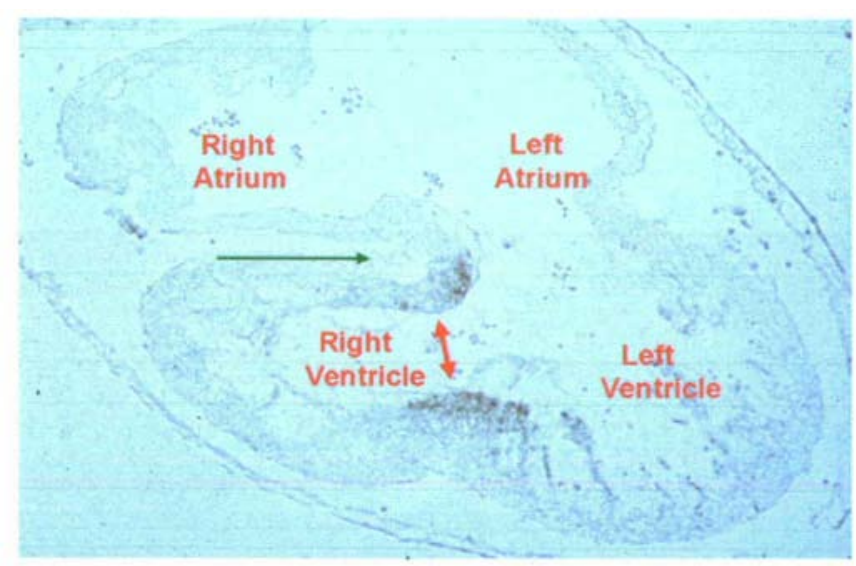

Figure 23.

This section of a beart from a buman embryo has been incubated with an antibody to the nodose ganglion from the chick beart. The antibody demonstrates a ring of cells which surrounds the primary interventricular foramen (between red arrows). It shows bow the primary muscular ventricular septum separates the developing ventricular apical components. Note the deeply infolded right atrioventricular groove (Black arrow), and that the atrial chambers connect, at this stage, only to the developing left ventricle. Reproduced by kind permission of Profs Antoon Moorman and Wout Lamers, Department of Anatomy, University of Amsterdam. stained cells, these cells themselves developing to become the atrioventricular conduction axis. The septum carrying this axis, therefore, is the primordium of the apical muscular ventricular septum. This situation in the developing heart is directly analogous to the arrangement seen in postnatal hearts with double inlet left ventricle, and in the variant of tricuspid atresia produced by absence of the right atrioventricular connection.

The evidence advanced by the group from Boston to support the concept that the rudimentary chamber represents only the infundibulum comes from hearts with "two-chambered right ventricle". They argue that, in these malformations, the distal chamber represents the sequestrated infundibulum. But an equally valid explanation can be provided on the basis that the distal chamber is formed by division of the apical component in consequence of hypertrophy of the apical extent of the septomarginal trabeculation. Indeed, in many normal hearts, the apical part of this trabeculation is found dividing the right ventricular apex into extensions of the inlet and outlet ventricular components, but with both recesses having trabeculations of unequivocally right ventricular pattern (Fig. 24). In abnormal hearts, these recesses can themselves be separated in such a way that the distal apical component becomes sequestrated from the right ventricle, and haemodynamically part of the left ventricle..$^{21,22}$ The recess to be found extending antero-superiorly from the left ventricle, however, is readily recognised, on the basis of the pattern of its trabeculations as part of the right ventricle.

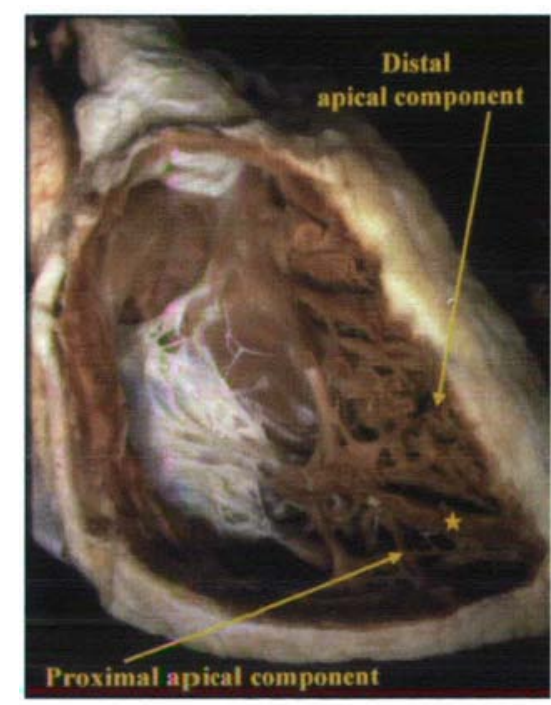

Figure 24.

In this normal right ventricle from an adult beart, the apical part of the septomarginal trabeculation (star) produces two apical extensions. Both bave coarse trabeculations, indicating that the shelf has divided the apical component of the ventricle. 
All the findings, therefore, be they derived from the normal or from abnormal hearts, are fully consistent with the notion that, in hearts with double inlet left ventricle and tricuspid atresia, the anterior chamber is the rudimentary and incomplete right ventricle, and not simply the infundibulum. These hearts, therefore, in anatomic terms, possess two ventricles, a big one of left ventricular morphology, and a second incomplete and hypoplastic one of right ventricular morphology. Surgical correction of such hearts, nonetheless, will almost always be achieved by creating a univentricular circulation by means of the Fontan procedure or one of its variants. Hence, in functional terms the ventricular mass is univentricular.

The discrepancy between the anatomical and functional situations was exemplified by earlier experience when patients with tricuspid atresia were corrected surgically by construction of an atrioventricular connection. The increased flow through the rudimentary right ventricle could then produce marked growth of its apical component. At the same time, it was the exception rather than the rule for the rudimentary ventricle to become a true pumping chamber. ${ }^{23}$ Despite the potential size of the second chamber, which emphasised the obvious anatomic biventricular nature of the heart (Fig. 25), in almost all instances the ventricular mass remained stubbornly univentricular in terms of its function.

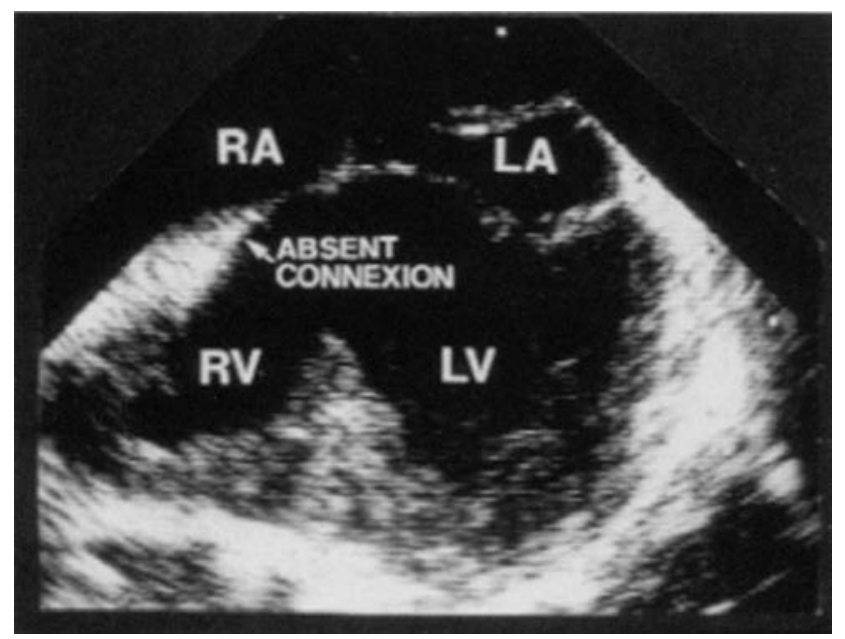

Figure 25.

This cross-sectional echocardiogram, from a patient with tricuspid atresia, sbows absence of the right atrioventricular connection and a good-sized rudimentary right ventricle $(R V)$. Despite the size of the ventricle, it cannot safely be incorporated into the circulation, which is functionally univentricular despite the obvious anatomic biventricular nature of the ventricular mass. $R A$ - right atrium; $L A$ - left atrium; $L V$ - left ventricle.

\section{Is there a truly univentricular heart?}

Questions continue concerning the existence of a heart with a truly solitary ventricular mass. In many hearts with an apparently common ventricular chamber, an hypoplastic apical septum is found which separates apical components of right and left ventricular morphology, respectively. Such hearts are no more than huge ventricular septal defects (Fig. 26), with biventricular atrioventricular connections. In other hearts which seem, at first sight, to possess solitary ventricles of either right or

(a)

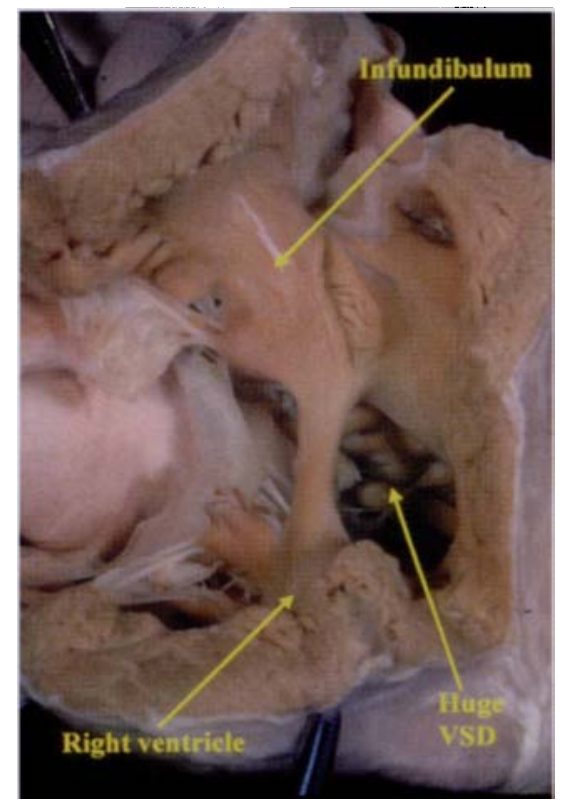

(b)

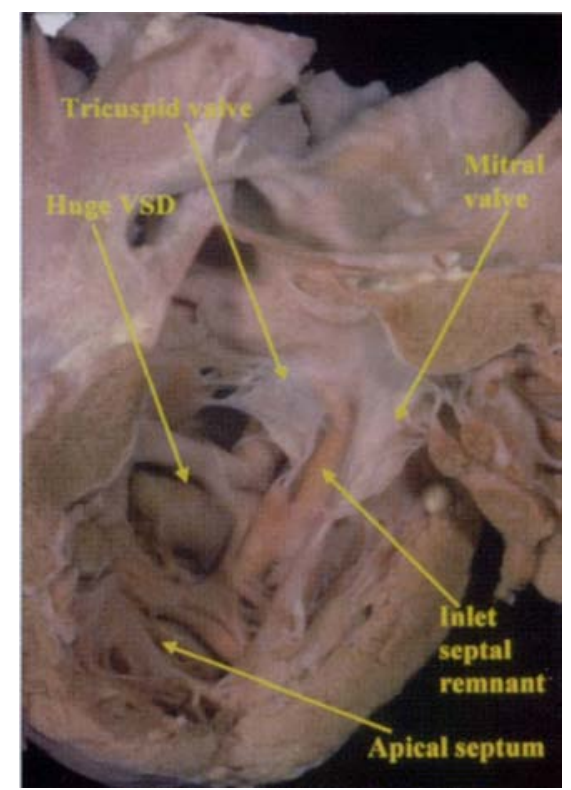

Figure 26.

The larger part of the ventricular septum is lacking in this heart, shown from its right (a) and left (b) ventricular aspects. The apical septal remnant, nonetbeless, separates apical components of right and left ventricular morpbology. This is a huge ventricular septal defect. 
left morphology, careful postmortem dissection, often guided by the delimiting ventricular arteries, reveals the presence of a second, extremely hypolastic, ventricular apical component found either in the inferior or superior wall of the ventricular mass. In some of these cases, histological examination may be needed to demonstrate the second ventricle. Such microscopic study confirms the septal nature of the muscular structure, since it is then shown to carry the ventricular conduction tissues. The key to existence of a solitary ventricle, therefore, is once more to be found in the arrangement of the septal structures. This is because, in very rare hearts, the only septal structure to be found within the ventricular mass is the muscular septum separating the subaortic and subpulmonary outlets. In these hearts, the apical trabeculations are exceedingly coarse, and extend throughout the apical regions (Fig. 27). Histological examination confirms the absence of any apical septal structures (Fig. 28), with the conduction axis descending as a strand of conduction tissue within the parietal ventricular wall. ${ }^{24}$

\section{Do other hearts possess a functionally single ventricular mass?}

Thus far, we have confined our discussion of hearts with one big and one small ventricle to those in which the atrioventricular connections are univentricular, ${ }^{5,6}$ or those in which there is truly a solitary ventricle. Patients with this type of heart, nowadays, are generally suitable for surgical palliation by means of a Fontan or similar procedure,

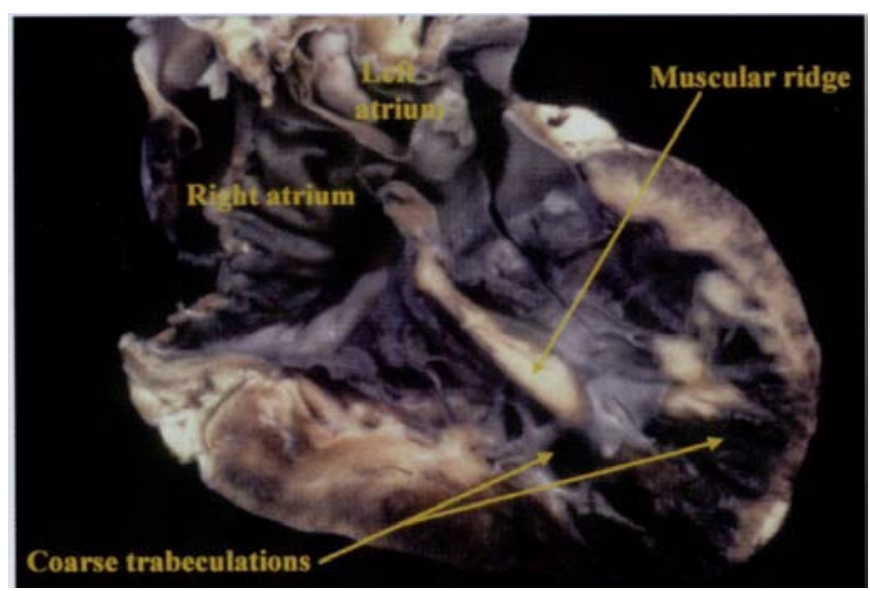

Figure 27.

This four-chamber section shows double inlet to a solitary and indeterminate ventricle. The section has passed through a posterior muscular ridge, but this is not a septum, since the entirety of the ventricular apex bas very coarse trabeculations.

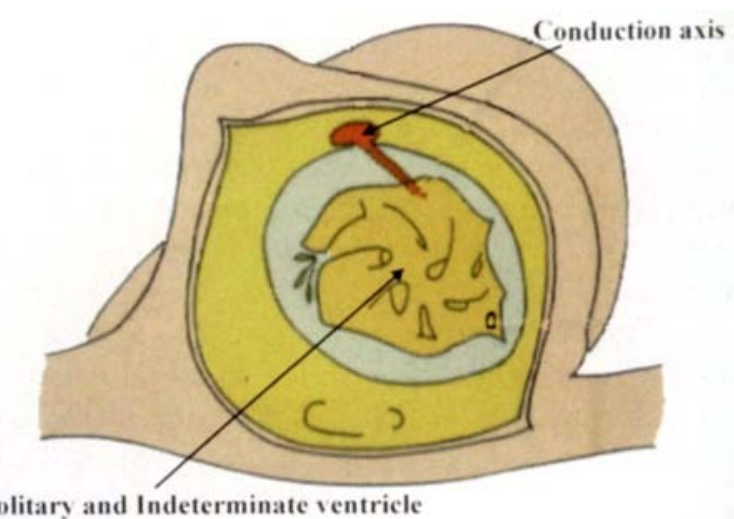

Figure 28.

This diagram illustrates the disposition of the atrioventricular conduction tissue in hearts such as shown in Fig. 27 with a solitary and indeterminate ventricle as seen through the right atrium. The parietal position of the conducting patbway confirms that the posterior ridge is not a remnant of the muscular ventricular septum.

thus creating a functionally univentricular circulation. Occasionally they are suitable for surgical septation to create a biventricular circulation, but it is still appropriate to describe these hearts as functionally univentricular, since the dominant left ventricle is then divided surgically to pump into both newly created circulations. There are other conditions, however, in which, despite the obvious biventricular arrangement of the ventricular mass, and the presence of biventricular atrioventricular connections, the only surgical options rely postoperatively on a functionally univentricular circulation. These are the hearts with hypoplasia of one or other ventricle in the presence of either atresia or severe stenosis of its outflow tract, or other hearts where complex problems, such as straddling atrioventricular valves, militate against surgical construction of a biventricular circulation. As already emphasised, in these latter hearts there is no question concerning the biventricular anatomical arrangement. Oftentimes the cavity of the hypoplastic ventricle, containing all its component parts but small because of gross mural hypertrophy, is much smaller than the cavity of the incomplete right ventricles found in hearts with univentricular connection to a dominant left ventricle. Properly to account for all these anatomic variations, therefore, and to make the necessary functional correlations, it is surely preferable to us to use the adjective "single", or the prefix "uni", in a literally accurate sense when applied to the ventricular mass. As we have shown, this is now readily achieved by distinguishing the functionally univentricular arrangement from that seen when the ventricular mass is solitary from the anatomic stance. The latter arrangement is very rare. In fact, 
the majority of hearts which are presently described as having "single ventricles", or "univentricular hearts", are much better described in terms of imbalance of the ventricular mass. Precision in diagnosis is then provided by additional description of the atrioventricular connections, which frequently are truly univentricular.

\section{Conclusions}

The one area of description of congenitally malformed hearts which remains markedly contentious in the current era is that involving the use of the term "single ventricle", or "univentricular heart". If those who continue to espouse the use of these terms for description of hearts possessing more than one chamber within the ventricular mass had shown scientifically that the second chamber was not a ventricle, we could understand their stance. This is not the case. Thus, hearts with double inlet left ventricle are said to possess a "single left ventricle". ${ }^{25}$ In reality, in such hearts, all the morphological evidence points to the second chamber being a rudimentary and incomplete right ventricle, as is the second chamber in hearts with tricuspid atresia. There is no evidence of which we are aware to show that the chamber is simply an infundibulum. This is because its apical component is separated from the dominant left ventricle by the apical ventricular septum, which carries the ventricular conduction tissues on its crest, and which is nourished by the perforating septal branches of the interventricular coronary arteries. Further evidence confirming that the chamber is the remnant of the right ventricle comes from "subtraction" studies. If the chamber was simply an infundibulum, it would not exist in those hearts with double inlet to, and double outlet from, the dominant left ventricle. Exactly the same logic which dictates that "large right ventricle together with small left ventricle does not equal univentricular heart" ventricle together with small right ventricle" similarly does not equal univentricular heart. The solitary and indeterminate ventricle is the only anatomical example of a single ventricle or univentricular heart. This must be differentiated from the much larger collection of hearts which are functionally univentricular, and suitable only for univentricular surgical palliation.

\section{Acknowledgement}

Professor Robert H. Anderson is supported by the 'Joseph Levy Foundation and the British Heart Foundation.

\section{References}

1. Anderson RH, Ho SY, Rigby ML. The morphologic variability in atrioventricular valvar atresia. Cardiol Young 2000;10:32-41.

2. Van Praagh R, Ongley PA, Swan HJC. Anatomic types of single or common ventricle in man: morphologic and geometric aspects of sixty necropsied cases. Am J Cardiol $1964 ; 13: 367-386$.

3. Edwards JE. Discussion. In: Davila JC (ed) 2nd Henry Ford Hospital International Symposium on Cardiac Surgery, Appleton-Century-Crofts, New York, 1977; pp 242-242.

4. Anderson RH, Becker AE, Freedom RM, Quero-Jimenez M, Macartney FJ, Shinebourne EA, Wilkinson JL, Tynan MJ. Problems in the nomenclature of the univentricular heart. Herz 1979; 4:97-106.

5. Anderson RH, Macartney FJ, Tynan M, Becker AE, Freedom RM, Godman MJ, Hunter S, Quero Jim,nez M, Rigby ML, Shinebourne EA, Sutherland GR, Smallhorn JF, Soto B, Thiene G, Wilkinson JL, Wilcox BR, Zuberbuhler JR. Univentricular atrioventricular connection: the single ventricle trap unsprung. Pediatr Cardiol 1983; 4:273-280.

6. Anderson RH, Becker AE, Tynan M, Macartney FJ, Rigby ML, Wilkinson JL. The univentricular atrioventricular connection: getting to the root of a thorny problem. Am J Cardiol 1984; 54:822-828

7. Van Praagh R, Wise JRJ, Dahl BA, Van Praagh S. Single left ventricle with infundibular outlet chamber and tricuspid valve opening only into outlet chamber in 44-year-old man with thoracoabdominal ectopic cordis without diaphragmatic or pericardial defect: Importance of myocardial morphologic method of chamber identification in congenital heart disease. In: Van Praagh R, Takao A (eds) Etiology and Morphogenesis of Congenital Heart Disease. Futura Publishing Company, Mount Kisco, New York, 1980; pp. 379-420.

8. Van Praagh R, David I, Wright GB, Van Praagh S. Large RV plus small LV is not single RV. Circulation 1980;61:1057-1058.

9. Uemura $H, H_{0} S Y$, Devine WA, Kilpatrick LL, Anderson RH. Atrial appendages and venoatrial connections in hearts from patients with visceral hetertotaxy. Ann Thorac Surg 1995;60:561-569.

10. Goor DA, Lillehei CW. Congenital Malformations of the Heart. New York: Grune and Stratton, 1975; pp 1-32.

11. Soto B, Becker AE, Moulaert AJ, Lie JT, Anderson RH. Classification of ventricular septal defects. $\mathrm{Br}$ Heart J 1980;43:332-343.

12. Anderson RH, Brown NA. The anatomy of the heart revisited. Anat Rec 1996;246:1-7.

13. Gatzoulis MA, Soukias ND, Ho SY, Josen M, Anderson RH. Echocardiographic-morphologic correlations in tetralogy of Fallot. Eur Heart J 1999;20:221-231.

14. Van Praagh R, Van Praagh S, Nebesar RA, Muster AJ, Sinha SN, Paul MH. Tetralogy of Fallot: underdevelopment of the pulmonary infundibulum and its sequelae. Report of a case with cor triatriatum and pulmonary sequestration. Am J Cardiol 1970;26:25-33.

15. Becker AE, Connor M, Anderson RH. Tetralogy of Fallot: a morphometric and geometric study. Am J Cardiol 1975;35:402-412.

16. Isaaz K, Cloez JL, Danchin N, Marcon F, Worms AM, Pernot C. Right ventricular outflow tract assessment by two-dimensional echocardiography in children using a new subcostal view. An angiographic and morphologic correlative study. Am J Cardiol 1985;56:539-545.

17. Keeton BR, Macartney FJ, Hunter S, Mortera C, Rees P, Shinebourne EA, Tynan M, Wilkinson JL, Anderson RH. Univentricular heart of right ventricular type with double or common inlet. Circulation 1979;59:403-411. 
18. Deanfield JE, Tommasini G, Anderson RH, Macartney FJ. Tricuspid atresia: an analysis of the coronary artery distribution and ventricular morphology. Br Heart J 1982;48:485-492.

19. Kumar K, Lock JE, Geva T. Apical muscular ventricular septal defects between the left ventricle and the right ventricular infundibulum: diagnostic and interventional considerations. Circulation 1997;95:1207-1213.

20. Lamers WH, Wessels A, Verbeek FJ, Moorman AFM, Virágh S, Wenink ACG, Gittenberger-de Groot AC, Anderson RH. New findings concerning ventricular septation in the human heart. Implications for maldevelopment. Circulation 1992;86:11941205.

21. Beirzke A, Anderson RH, Wilkinson JL, Shinebourne EA. Twochambered right ventricle: simulating two-chambered left ventricle. Br Heart J 1979;42:22-26.
22. Capuani A, Uemura $\mathrm{H}$, Ho SY, Anderson RH. Anatomic spectrum of abnormal ventriculoarterial connections: surgical implications. Ann Thorac Surg 1995; 95:352-360.

23. Gewillig MH, Lundstrom UR, Bull C, Wyse RKH, Deanfield JE. Exercise responses in patients with congenital heart disease after Fontan repair: Patterns and determinants of performance. J Am Coll Cardiol 1990; 15: 1424-1432.

24. Wilkinson JL, Anderson RH, Arnold R, Hamilton DI, Smith A. The conducting tissues in primitive ventricular hearts without an outlet chamber. Circulation 1976;53:930-938.

25. Bevilacqua M, Sanders SP, Van Praagh S, Colan SD, Parness I. Double-inlet single left ventricle: echocardiographic anatomy with emphasis on the morphology of the atrioventricular valves and ventricular septal defect. J Am Coll Cardiol 1991;18:559-568. 